\title{
Microstructure and microhardness of an Al-6061 metal matrix composite processed by high-pressure torsion
}

\author{
Saleh N. Alhajeri ${ }^{\mathrm{a},}$, Khaled J. Al-Fadhalah ${ }^{\mathrm{b}}$, Abdulla I. Almazrouee ${ }^{\mathrm{a}}$, Terence G. Langdon ${ }^{\mathrm{c}, \mathrm{d}}$ \\ ${ }^{a}$ Department of Manufacturing Engineering, College of Technological Studies, P.A.A.E.T., P.O. Box 42325, \\ Shuwaikh 70654, Kuwait \\ ${ }^{b}$ Department of Mechanical Engineering, College of Engineering \& Petroleum, Kuwait University, P.O. Box 5969, \\ Safat 13060, Kuwait \\ ${ }^{c}$ Materials Research Group, Faculty of Engineering and the Environment, University of Southampton, Southampton \\ SO17 1BJ, UK \\ ${ }^{d}$ Departments of Aerospace \& Mechanical Engineering and Materials Science, University of Southern California, \\ Los Angeles, CA 90089-1453, USA
}

\begin{abstract}
Disks of an Al-6061 metal matrix composite, reinforced with 10 vol.\% $\mathrm{Al}_{2} \mathrm{O}_{3}$ particles, were processed by high-pressure torsion (HPT) at room temperature for 1/4, 1/2, 1,5 and 10 turns under an applied pressure of $6.0 \mathrm{GPa}$. The evolution of microstructure was investigated using optical microscopy and scanning electron microscopy. During HPT processing the average grain size within the aluminum matrix decreased from $\sim 35 \mu \mathrm{m}$ in the unprocessed condition to $170 \mathrm{~nm}$ after processing through 10 turns but there was no significant effect on the size and distribution of the alumina particulate clusters. The values of the Vickers microhardness were recorded across the surface of each disk and then plotted as two-dimensional and threedimensional color-coded contour maps. The results show the hardness increases from $\sim 56 \mathrm{Hv}$ in the initial condition to $\sim 165 \mathrm{Hv}$ after HPT for 10 turns. The results demonstrate that, as in many unreinforced metallic alloys, the evolution of hardness with strain exhibits strain hardening without any significant recovery.
\end{abstract}

Keywords: composites; grain refinement; high-pressure torsion; microhardness; microstructure.

* Corresponding Author. E-mail address: sn.alhajeri@paaet.edu.kw (S. N. Alhajeri) 


\section{Introduction}

There have been extensive investigations over the last two decades into the production of bulk ultrafine-grained materials through the application of severe plastic deformation (SPD). In practice, most SPD processing is generally conducted using either equal-channel angular pressing (ECAP) [1] or high-pressure torsion (HPT) [2] where experiments show these procedures provide the capability of refining the grain size of a bulk polycrystalline solid to the submicrometer or even the nanometer range. Furthermore, these processes produce superior properties such as high strength and, if the grains exhibit reasonable thermal stability, an opportunity to achieve excellent superplastic properties at elevated temperatures [3]. It is now recognized that processing by HPT is especially effective by comparison with ECAP because it produces both smaller grain sizes [4,5] and a higher fraction of grain boundaries having high angles of misorientation [6]. This effect is due to the concurrent application of high pressure and torsional straining during the HPT processing.

Most HPT studies have been applied to metals and their alloys such as $\mathrm{Al}, \mathrm{Mg}, \mathrm{Ni}$ and $\mathrm{Cu}$ [715] and the emphasis has been placed on examining the effect of HPT strain on microstructural homogeneity and the evolution of mechanical properties. This includes investigations of the grain size, the grain boundary structure, the presence of dislocations and other imperfections, the thermal stability of the microstructure, the extent of hardness homogeneity and the mechanical properties revealed through subsequent tensile testing. In addition, there are a limited number of experimental studies on the SPD processing of alloys containing hard particles such as metal matrix composites (MMCs).

The first application of SPD processing to an MMC was in experiments conducted in 1999 in which an Al-6061 alloy reinforced with 10 vol.\% $\mathrm{Al}_{2} \mathrm{O}_{3}$ particulates was processed in two 
different ways. First by ECAP to a total of 8 passes at $673 \mathrm{~K}$ and an additional 2 passes at $473 \mathrm{~K}$ to give a total strain of $\sim 10$ and then by HPT at room temperature to a strain of $\sim 7$ [16]. Inspection after processing showed the grain size was reduced from an initial value of $\sim 35 \mu \mathrm{m}$ to values of $\sim 0.6 \mu \mathrm{m}$ and $\sim 0.2 \mu \mathrm{m}$ after ECAP and HPT, respectively, and the hardness was increased from an initial value of $\sim 650 \mathrm{MPa}$ to $\sim 1200 \mathrm{MPa}$ after ECAP and $\sim 1600 \mathrm{MPa}$ after HPT. It was also reported that there was no evidence for any breaking of the $\mathrm{Al}_{2} \mathrm{O}_{3}$ particles during the processing by ECAP. Later experiments on the same composite revealed some limited cracking of the alumina particulates when processing by ECAP at room temperature with the average particulate size reduced from an initial value of $\sim 7.5 \mu \mathrm{m}$ to $\sim 7.2 \mu \mathrm{m}$ after 5 passes [17]. In another study, a similar composite was processed by ECAP for one pass at room temperature and an additional 11 passes at $473 \mathrm{~K}$ to give a total strain of $\sim 12$ and the grain size was reduced to $\sim 1.9 \mu \mathrm{m}$ while the average particulate size remained unchanged at $\sim 270 \mathrm{~nm}[18]$.

Several reports are now available on the processing of MMCs by HPT [19-33]. For example, Al-6061 MMCs were processed by HPT at room temperature under a pressure of 5.0 GPa with two different sets of reinforcement particles (20 vol.\% $\mathrm{Al}_{2} \mathrm{O}_{3}$ or $\left.10 \mathrm{vol} . \% \mathrm{SiC}\right)$ [20]. The results revealed no evidence for any particle fracture and no significant change in the shapes of the dense particle clusters after processing by HPT even after very high strains. More recently, an HPT study of an Al-6061 MMC reinforced with 20 vol. $\% \mathrm{Al}_{2} \mathrm{O}_{3}$ particles showed the matrix grains were equiaxed after 5 turns with an average size of $\sim 80 \mathrm{~nm}$ which was significantly smaller than the initial grain size of $\sim 35 \mu \mathrm{m}$ [25]. It is interesting to note also that the matrix grain size of the Al-6061 MMC was smaller than the grain size of 120 nm for the unreinforced Al-6061 alloy processed under similar HPT conditions. Finally, a very recent report for HPT processing of an Al-7075 alloy reinforced with 10 vol. $\% \mathrm{Al}_{2} \mathrm{O}_{3}$ particulates showed the potential 
for achieving true superplastic elongations of up to $>600 \%$ when pulling HPT-processed samples in tension at a temperature of $623 \mathrm{~K}$ [33].

These studies show that HPT is an effective method for achieving excellent grain refinement in the aluminum matrix of Al-based MMCs. Nevertheless, the evolution of hardness homogeneity during HPT processing has not been fully documented for these MMCs. Accordingly, the present investigation was initiated to examine the effect of HPT on microstructural refinement and the development of hardness homogeneity in an Al-6061 metal matrix composite reinforced with 10 vol. $\% \mathrm{Al}_{2} \mathrm{O}_{3}$ particles. This composite was selected because earlier studies demonstrated the successful processing of this material using both HPT [16] and ECAP [16-18,34,35]

\section{Experimental material and procedures}

The experiments were performed using a metal matrix composite consisting of Al-6061 as the matrix alloy reinforced with 10 vol. $\%$ of $\mathrm{Al}_{2} \mathrm{O}_{3}$ particles. Detailed information about this material was given in earlier reports $[16,17]$. The as-received material was machined and cut into disks having diameters of $10 \mathrm{~mm}$ and thicknesses of $\sim 1.2 \mathrm{~mm}$ and these disks were then polished on both surfaces to mirror-like surfaces and final thicknesses of $\sim 0.8 \mathrm{~mm}$. The disks were processed by HPT in air at room temperature under an applied load of 48 tons which is equivalent to an imposed pressure of $6.0 \mathrm{GPa}$. As illustrated in Fig. 1, the HPT processing was conducted using upper and lower anvils fabricated from high-strength tool steel. For HPT processing, a disk was placed in a spherical cavity on the upper surface of the lower anvil where this cavity had a diameter of $10 \mathrm{~mm}$ and a depth of $0.25 \mathrm{~mm}$. The upper anvil also had a similar cavity on its lower surface and the two anvils were then brought together so that pressure was applied to the disk under quasi-constrained conditions where there is a limited outflow of 
material around the periphery of the disk between the two anvils [36,37]. Torsional straining was applied to the disk by rotating the lower anvil concurrently with the application of the applied pressure. For these experiments, the speed of anvil rotation was $1 \mathrm{rpm}$ and the disks were processed monotonically for totals of $1 / 4,1 / 2,1,5$ and 10 turns.

Following HPT, the disks were prepared for metallographic examination. Each disk was cold mounted and then ground using SiC papers with grits between 240 and 1200 and using water as a coolant. Polishing was performed using 9, 6 and $3 \mu \mathrm{m}$ diamond pastes and then there was a final polish with colloidal silica. Optical microscopy (OM) images were taken using a Zeiss optical Axio-Imager microscope. The OM images were taken at the surface of each disk at three positions: near the center, at the mid-radius position and near the edge of the disk. The cross-section of each disk was prepared by ion-milling using a JEOL JSM-9001 cross-section polisher for further microstructural analysis using a JEOL JSM-7001F field-emission scanning electron microscope (SEM). Backscattered electron imaging (BEI) was used to record micrographs which were taken near the center of each disk and near the edge. The grain sizes at the near-edge positions were measured after each turn using the linear intercept method.

Measurements of the Vickers mcrohardness, Hv, were taken on the surface of each disk using an InnovaTest 413-D Vickers hardness tester. These measurements were recorded using an applied load of $200 \mathrm{gf}$ and a dwell time of 15 s. Measurements were recorded at points separated by $0.3 \mathrm{~mm}$ on the $X$ and $Y$ axes starting from a point at the center of each disk, where $X$ and $Y$ denote two orthogonal axes with a point of intersection at $(0,0)$ at the center of the disk. The average microhardness measurements in the as-received unprocessed condition were also recorded and plots were developed showing the microhardness values along the diameters of the disks both in the unprocessed condition and after processing for selected numbers of turns. To 
provide an overall visual presentation of the hardness data, two-dimensional color-coded contour maps and three-dimensional representations of the microhardness measurements were constructed for each disk after HPT showing the evolution in microhardness with increasing numbers of turns. Finally, following the proposal presented earlier [38], the microhardness measurements were plotted against the equivalent von Mises strain, $\varepsilon_{\mathrm{eq}}$, where the strain is calculated using the relationship $[39,40]$ :

$$
\varepsilon_{e q}=\frac{2 \pi r N}{\sqrt{3} h}
$$

where $r$ is the radius of the disk, $N$ is the number of turns and $h$ is the thickness of the disk.

\section{Experimental results}

\subsection{Microstructures before and after HPT}

The OM micrographs in Fig. 2 show the microstructures at the near-edge positions for (a) the initial or unprocessed material and after HPT processing through (b) $1 / 4$, (c) $1 / 2$, (d) 1 , (e) 5 and (f) 10 turns. These micrographs show clearly the presence of alumina particulates and the occurrence of some clustering or agglomeration. Generally, this clustering is categorized into two types: coarse or dense particle clusters and fine or diffuse clusters, where both of these types are visible throughout Fig. 2. It is also apparent that the clustering is present in the unprocessed material and in all samples after HPT processing although generally it appears that the clustering size decreases slightly with increasing numbers of turns and there appears to be a more uniform distribution of particles in Fig. 2(f). Nevertheless, the HPT straining generally has only a negligible effect on the size and the distribution of the $\mathrm{Al}_{2} \mathrm{O}_{3}$ reinforcement particles and there was no significant differences in the particulate sizes in the various micrographs shown in Fig. 2(a) to (f). This confirms an earlier report for the same MMC that there is only a very minor 
reduction in the average particulate size when processing by ECAP through 5 passes [17].

Phase contrast mapping is shown in Fig. 3 where (a) is the unprocessed material and (b), (c), (d) and (e) show the same field of view for the major elements of $\mathrm{Al}, \mathrm{O}, \mathrm{Mg}$ and $\mathrm{Si}$, respectively. These observations confirm that the clusters of $\mathrm{Al}_{2} \mathrm{O}_{3}$ particles are essentially randomly dispersed in the matrix and also dispersed within the Al matrix there are random distributions of the hardening precipitates of $\mathrm{Mg}_{2} \mathrm{Si}$.

Figure 4 presents BEI images of the microstructures of the cross-sections of the HPT disks for the unprocessed condition and after HPT processing through 1/4 to 10 turns and similar images are shown in Fig. 5 for the near-edge position. For the unprocessed disk in Fig. 4(a) the average grain size is $\sim 35 \mu \mathrm{m}$ and there are dense clusters of $\mathrm{Al}_{2} \mathrm{O}_{3}$ particles with average sizes of $\sim 7.5 \mu \mathrm{m}$ as also reported in an earlier study on the same MMC [17]. It is apparent that grain refinement occurs rapidly in Fig. 4(b-f) and generally the microstructure consists of elongated grains of a few micrometers for $N \leq 1$ turn but this transforms into equiaxed and refined grains of a submicrometer size for $N \geq 5$ turns. It appears also that there is little or no reduction in the size of the fine particles of $\mathrm{Al}_{2} \mathrm{O}_{3}$ with increasing numbers of HPT turns. The grain refinement is even more rapid at the near-edge location because of the higher imposed strain as demonstrated in Fig. 5. Compared to the center position, the average grain size was reduced after processing by $N=1 / 4$ turn to elongated grains with a size of $\sim 230$ to $350 \mathrm{~nm}$ in Fig. 5(b) and with increasing HPT turns the grains became more equiaxed and smaller. Thus, in Fig. 5(c-f) the average grain sizes were measured as $\sim 250, \sim 200, \sim 200$ and $\sim 170 \mathrm{~nm}$ after processing by HPT for $N=1 / 2,1,5$ and 10 turns, respectively.

\subsection{Microhardness measurements}

The microhardness profiles along the diameters of HPT disks are shown in Fig. 6 for 
increasing numbers of turns, where the lower line shows the measured hardness of $\mathrm{Hv} \approx 56$ for the unprocessed material. It is apparent that processing through $1 / 4$ turn produces very significant increases in hardness at the edges of the disks with values up to $\mathrm{Hv} \approx 140$ whereas in the center of the disk the hardness increases only marginally to $\mathrm{Hv} \approx 62$. At the two edges, the results are essentially symmetrical with respect to the central point. Thereafter, there is a relatively minor increase in hardness at the edges, with final values of $\mathrm{Hv} \approx 170$ after 10 turns and in the center the hardness increases only to $\mathrm{Hv} \approx 110$. Thus, there remains a significant inhomogeneity in the hardness even after 10 revolutions and the region of lower hardness occupies an area having a radius of $<1 \mathrm{~mm}$ around the central point. In many materials the hardness develops a general homogeneity after processing by HPT through 10 or more turns but the results from earlier experiments on an Al-7075 $\mathrm{MMC}$ reinforced with 10 vol.\% $\mathrm{Al}_{2} \mathrm{O}_{3}$ particles showed also that the hardness was not homogeneous after 20 turns [33]. There are also some examples where hardness homogeneity is not achieved in unreinforced metals even after processing through very large numbers of turns: for example, 40 turns in a $\mathrm{Ni}-50 \% \mathrm{Ti}$ shape memory alloy [41] and 50 turns in a Ti-24\% Nb-4\% Zr-8\% Sn (wt.\%) $\beta$-alloy [42].

Figure 7 presents an overall pictorial display of the microhardness values across disks processed through $1 / 4$ to 10 turns where the colors represent different hardness values in increments of 20 with the color key at lower right having values from 60 to 200. These twodimensional color-coded contour maps were introduced several years ago to provide a visual display of the local variations in hardness over the total surfaces of specimens processed by ECAP [43] or HPT [8]. Similarly, and following an approach introduced recently [44], the hardness variations may be presented also using three-dimensional representations as shown in Fig. 8.

For the disk processed by 1/4 turn in Fig. 7(a) the hardness is very inhomogeneous 
around the central point. In Fig. 8(a) in three dimensions there is a sharp cone around the center of the disk which becomes wider at a distance of $\sim 0.5 \mathrm{~mm}$ from the center. For $1 / 2$ turn the hardness becomes more homogeneous at $\sim 3 \mathrm{~mm}$ from the center in Fig. 7(b) and the threedimensional representation in Fig. 8(b) shows a slightly wider cone. This trend continues with increasing numbers of turns until ultimately, at 10 turns, Figs 7(e) and 8(e) demonstrate a significant increase in the extent of homogeneity with the central region in the three-dimensional representation now depicted as a very narrow spike.

Although the results in Fig. 6 appear to show an essentially random distribution of datum points, it was suggested in early experiments on HPT processing that these same points may be brought onto a single curve by plotting each hardness value against the equivalent von Mises strain as calculated from eq. (1) [38]. To check this trend, Fig. 9 shows the various datum points of Fig. 6 replotted in this normalized form so that the evolution in hardness is now clearly displayed. Thus, the hardness increases rapidly in the very early stages of straining but the microhardness essentially saturates at a strain of $\sim 50$ and thereafter, at even higher strains, the microhardness is reasonably saturated at a value of $\mathrm{Hv} \approx 165$. These results show a typical trend of strain hardening without any significant recovery as observed in many different metals and alloys processed by HPT [45]. For these materials, the hardness often saturates at strain values above $\sim 10$ or 15 but in some materials the saturation occurs much later at strains above $\sim 150$ [46]. Thus, the present results are consistent with earlier data for unreinforced metallic alloys and the apparent fluctuations in the individual microhardness values between $\sim 155$ and $\sim 175$ in the saturation region are also similar to earlier results for unreinforced aluminum alloys; for example, Al-7075 [46,47] and Al-6061 [48-51]. 


\section{Discussion}

\subsection{Microstructural evolution in HPT processing}

Processing by HPT of the Al-based MMC used in this investigation shows the potential for achieving exceptional grain refinement and the development of excellent microstructural homogeneity. In general, there is a decrease in the grain size with increasing numbers of HPT turns from an initial value of $\sim 35 \mu \mathrm{m}$ to a minimum or saturation value of $\sim 170 \mathrm{~nm}$ after processing through $N=10$ turns. By contrast, the effect of HPT straining on the distribution and size of the $\mathrm{Al}_{2} \mathrm{O}_{3}$ particulates appears to be negligible. The average size of the dense particle clusters of $\sim 7.5 \mu \mathrm{m}$ remains essentially unchanged with increasing numbers of turns and there is also no significant change in the size and distribution of the diffuse particle clusters for any of the HPT samples. There appears to be a very limited reduction in the size of the $\mathrm{Al}_{2} \mathrm{O}_{3}$ particles due to HPT processing and this matches an earlier report where measurements on the same MMC after processing by ECAP for five passes showed the average particle size was reduced from $\sim 7.5 \mu \mathrm{m}$ in the unpressed condition to $\sim 7.2 \mu \mathrm{m}$ after pressing [17]. Another ECAP study on this MMC also suggested that the size of the reinforcement particles was unaffected even after 12 passes of ECAP [18].

It is reasonable to anticipate that processing by HPT may have a greater potential for breaking the particles due to the very high pressure applied during processing. An earlier investigation examined the use of HPT processing on the homogenization of reinforcement particles in two different MMCs (Al-6061 + 10 vol.\% SiC and Al-6061 + 20 vol.\% $\mathrm{Al}_{2} \mathrm{O}_{3}$ ) [20]. The Al6061 + 10 vol.\% SiC MMC was characterized by dense particle clusters so that homogenization was achieved only through intensive declustering at very large HPT strains (for example, $\varepsilon_{\mathrm{eq}} \approx 2300$ ). Thus, the declustering of the SiC particle clusters occurred specifically by 
a debonding of the particles from the dense cluster surfaces and subsequent diffusion into the particle-free matrix. By contrast, the $\mathrm{Al}-6061+20$ vol. $\% \mathrm{Al}_{2} \mathrm{O}_{3}$ composite contained mainly diffuse particle clusters and homogenization occurred via deformation of clusters at lower HPT strains (for example, $\varepsilon_{\mathrm{eq}} \approx 512$ ). In the present study, the maximum equivalent strain was $\varepsilon_{\mathrm{eq}} \approx$ 227 that was achieved at the edge of the disk at $\mathrm{N}=10$ turns. Therefore, it is reasonable to anticipate that the amount of strain imposed in this investigation was sufficient to cause only limited erosion of the dense clusters of $\mathrm{Al}_{2} \mathrm{O}_{3}$ particles rather than a full declustering and homogenization. At the same time, the diffuse clusters of $\mathrm{Al}_{2} \mathrm{O}_{3}$ particles tend to plastically deform without any measurable differences in their size or distribution. Consequently, as shown in Fig. 2 in this investigation, straining by HPT induces only very limited changes in the size and distribution of the $\mathrm{Al}_{2} \mathrm{O}_{3}$ particle clusters when the torsional straining is restricted to a maximum of 10 turns.

\subsection{Microhardness evolution in HPT processing}

The results from this investigation show that the microstructural evolution was accompanied by a very large increase in the microhardness of the MMC. Specifically, the microhardness increased from an unprocessed value of $\mathrm{Hv} \approx 56$ to a saturation value of $\mathrm{Hv} \approx 165$ after HPT through $N \geq 5$ turns. The dependence of the microhardness on the grain size is illustrated in Fig. 10. The microhardness measurements are related to the inverse square root of the grain size by a typical Hall-Petch linear relationship. This overall correlation between grain size and hardness was demonstrated in many earlier reports on unreinforced alloys of $\mathrm{Mg}$ [10], Al [12,48,49], $\mathrm{Cu}$ [52], and Ti [53]. Also, the saturation value of microhardness achieved after $N$ $=10$ turns for the Al-6061 MMC $(\sim 165 \mathrm{Hv})$ is in reasonable agreement with the hardness recorded in the unreinforced Al-6061 alloy after 5 turns ( 180 Hv) [50]. The difference in the saturation value between the two materials is most likely related to the initial condition of the 
material and the rate of grain refinement during HPT. An earlier study showed that samples of unreinforced Al-6061 alloy, which were initially subjected to T651 heat treatment, have an ultimate tensile strength (UTS) larger than the Al-6061-20\% $\mathrm{Al}_{2} \mathrm{O}_{3}$ composite while the latter has larger UTS than Al-6061 samples in the O-condition (annealed) [25]. After HPT, the UTS was highest for Al-6061-T651, followed by Al-6061-O, and lowest for the Al-6061 metal matrix composite. It was suggested that the rate of grain reduction produced by HPT has greater influence on the strength than the final grain size or secondary phases of the Al-6061 alloy. In the current study, the size of the $\mathrm{Al}_{2} \mathrm{O}_{3}$ particulates remained unaffected by the HPT process even after up to 10 turns. Consequently, it is suggested that the $\mathrm{Al}_{2} \mathrm{O}_{3}$ has limited effect on the grain refinement and ultimately on the microhardness of the Al-6061 composite.

The microhardness profiles shown in Figs. 6, 7 and 8 confirm the classic trend where the hardness is low near the center and it becomes high near the edges of the disk after processing by HPT. This is consistent with eq. (1) where the strain is low in the center of the disk where $r=0$. Nevertheless, the hardness increases and starts to become more homogeneous with increasing numbers of turns as is evident in Fig. 6. For this MMC, the microhardness at fractional numbers of turns (i.e. $N=1 / 4$ and $1 / 2$ turn) increases linearly with increasing distance from the center of the disk and this trend matches the theoretical strain relationship in eq. (1). However, at higher numbers of turns (i.e. $N \geq 1$ turn), the microhardness values start to evolve into a homogeneous distribution which is consistent with a theoretical model for HPT processing based on strain gradient plasticity modeling [54].

For this MMC, the hardness evolution with increasing HPT strain exhibits strain hardening without any significant recovery as illustrated in Fig. 9, where this type of hardness evolution was recorded earlier in many unreinforced metals and alloys [45]. The saturation of 
the microhardness values at $\mathrm{Hv} \approx 165$ which is apparent in Fig. 9 occurs at an equivalent strain of $\sim 50$ and this is higher than the strain required to achieve grain refinement. However, it is also apparent from Fig, 9 that there are fluctuations in hardness around the saturation value at strains larger than $\sim 50$ and this is probably due, at least in part, to the dispersion of relatively large $\mathrm{Al}_{2} \mathrm{O}_{3}$ particles, with an average size of $\sim 7.5 \mu \mathrm{m}$, in the ultrafine-grained structure. Thus, it appears that this dispersion leads to local variations in the hardness values so that there are deviations around the saturation value of $\sim 165 \mathrm{Hv}$.

\section{Summary and conclusions}

a. An Al-6061 metal matrix composite, reinforced with 10 vol. $\% \mathrm{Al}_{2} \mathrm{O}_{3}$ particles, was processed by HPT for up to 10 turns to examine the significance of grain refinement and the evolution of hardness homogeneity with increasing strain.

b. The average grain size of the aluminum alloy matrix was reduced from $\sim 35 \mu \mathrm{m}$ in the unprocessed material to a minimum grain size of $\sim 170 \mathrm{~nm}$ after processing through 10 turns. The results show there is no significant effect on the size and distribution of the $\mathrm{Al}_{2} \mathrm{O}_{3}$ particle clusters during processing by HPT.

c. The evolution of microhardness with strain demonstrates strain hardening without any significant recovery. The microhardness at fractional numbers of turns ( $N \leq 1$ turn) increases linearly from $\sim 62 \mathrm{Hv}$ at the center of the disk to $\sim 140 \mathrm{Hv}$ near the edge, whereas at large numbers of turns, up to $N=10$ turns, the microhardness tends to become more homogeneous with a saturation of $\sim 170 \mathrm{Hv}$ at the outer region of the disk at equivalent strains above $\sim 50$. 


\section{Acknowledgements}

This work was supported by the Public Authority of Applied Education and Training in Kuwait under grant no. TS-12-13 with additional support provided by Kuwait University General Facility project (GE 01/07) for sample preparation, optical microscopy and SEM. The work of one of us was supported by the European Research Council under ERC Grant Agreement No. 267464-SPDMETALS (TGL). 


\section{References:}

1. Valiev RZ, Langdon TG. Principles of equal-channel angular pressing as a processing tool for grain refinement. Prog Mater Sci 2006;51:881-981.

2. Zhilyaev AP, Langdon TG. Using high-pressure torsion for metal processing: Fundamentals and applications. Prog Mater Sci 2008;53:893-979.

3. Langdon TG. Twenty-five years of ultrafine-grained materials: achieving exceptional properties through grain refinement. Acta Mater 2013;61:7035-59.

4. Zhilyaev AP, Kim BK, Nurislamova GV, Baró MD, Szpunar JA, Langdon TG. Orientation imaging microscopy of ultrafine-grained nickel. Scripta Mater 2002;46(8):575-80.

5. Zhilyaev AP, Nurislamova GV, Kim BK, Baró MD, Szpunar JA, Langdon TG. Experimental parameters influencing grain refinement and microstructural evolution during high-pressure torsion. Acta Mater 2003;51(3):753-65.

6. Wongsa-Ngam J, Kawasaki M, Langdon TG. A comparison of microstructures and mechanical properties in a $\mathrm{Cu}-\mathrm{Zr}$ alloy processed using different SPD techniques. J Mater Sci 2013;48:4653-60.

7. Horita Z, Langdon TG. Microstructures and microhardness of an aluminum alloy and pure copper after processing by high-pressure torsion. Mater Sci Eng 2005;A410-411:422-5.

8. Xu C, Horita Z, Langdon TG. The evolution of homogeneity in processing by highpressure torsion. Acta Mater 2007;55:203-12.

9. Alhajeri SN, Kawasaki M, Gao N, Langdon TG. The evolution of homogeneity during processing of aluminium alloys by HPT. Mater Sci Forum 2010;667-669:277-82.

10. Bai J, Xue F, Alhajeri SN, Langdon TG. Microstructural evolution of Mg-4Nd alloy processed by high-pressure torsion. Mater Sci Forum 2010;667-669:391-6.

11. Ni S, Wang YB, Liao XZ, Alhajeri SN, Li HQ, Ringer SP, Langdon TG, Zhu YT. Grain size effect on deformation twinning and de-twinning in a nanocrystalline Ni-Fe alloy. Mater Sci Forum 2010;667-669:181-6.

12. Rajinikanth V, Venkateswarlu K, Sen MK, Das M, Alhajeri SN, Langdon TG. Influence of scandium on an $\mathrm{Al}-2 \% \mathrm{Si}$ alloy processed by high-pressure torsion. Mater Sci Eng 2011;A528:1702-6.

13. Al-Fadhalah KJ, Alhajeri SN, Almazrouee AI, Langdon TG. Microstructure and microtexture in pure copper processed by high-pressure torsion. $J$ Mater Sci 2013;48:4563-72.

14. Almazrouee AI, Al-Fadhalah KJ, Alhajeri SN, Langdon TG. Microstructure and microhardness of OFHC copper processed by high-pressure torsion. Mater Sci Eng 2015;A641:21-8.

15. Sabbaghianrad S, Langdon TG. An evaluation of the saturation hardness in an ultrafinegrained aluminum 7075 alloy processed using different techniques. J Mater Sci 2015;50:4357-65.

16. Valiev RZ, Islamgaliev RK, Kuzmina NF, Li Y, Langdon TG. Strengthening and grain refinement in an Al-6061 metal matrix composite through intense plastic straining. Scripta Mater 1999;40:117-22.

17. Li Y, Langdon TG. Equal-channel angular pressing of an Al-6061 metal matrix composite. J Mater Sci 2000;35(5):1201-4. 
18. Kawasaki M, Huang Y, Xu C, Furukawa M, Horita Z, Langdon TG. A quantitative study of cavity development in the tensile testing of an aluminum metal matrix composite processed by equal-channel angular pressing. Mater Sci Eng 2005;A410-411:402-7.

19. Sabirov I, Pippan R. Formation of a W-25\% Cu nanocomposite during high pressure torsion. Scripta Mater 2005;52:1293-8.

20. Sabirov I, Kolednik O, Pippan R. Homogenization of metal matrix composites by highpressure torsion. Metall Mater Trans A 2005;36A:2861-70.

21. Sauvage $\mathrm{X}$, Pippan R. Nanoscaled structure of a $\mathrm{Cu}-\mathrm{Fe}$ composite processed by highpressure torsion. Mater Sci Eng 2005;A410-411:345-7.

22. Sabirov I, Pippan R. Characterization of tungsten fragmentation in a W-25\% Cu composite after high-pressure torsion. Mater Charact 2007;58:848-53.

23. Sauvage $\mathrm{X}$, Jessner P, Vurpillot F, Pippan R. Nanostructure and properties of a $\mathrm{Cu}-\mathrm{Cr}$ composite processed by severe plastic deformation. Scripta Mater 2008;58:1125-8.

24. Quelennec X, Menand A, Le Breton JM, Pippan R, Sauvage X. Homogeneous Cu-Fe supersaturated solid solutions prepared by severe plastic deformation. Phil Mag 2010;90:1179-95.

25. Xu C, Horita Z, Langdon TG. Mechanical properties of Al-6061 and an Al-6061 metal matrix composite processed by high-pressure torsion. Mater Sci Forum 2011;667-669:689-94.

26. Edalati K, Iwaoka H, Horita Z, Konno M, Sato T. Unusual hardening in $\mathrm{Ti} / \mathrm{Al}_{2} \mathrm{O}_{3}$ nanocomposites produced by high-pressure torsion followed by annealing. Mater Sci Eng 2011;A529:435-41.

27. Wurster S, Gludovatz B, Hoffmann A, Pippan R. Fracture behaviour of tungstenvanadium and tungsten-tantalum alloys and composites. J Nucl Mater 2011;413:166-76.

28. Tian YZ, Zhang ZF, Langdon TG. Achieving homogeneity in a two-phase $\mathrm{Cu}-\mathrm{Ag}$ composite during high-pressure torsion. J Mater Sci 2013;48:4606-12.

29. Ekiz EH, Lach TG, Averback RS, Mara NA, Beyerlein IJ, Ponryazdan M, Hahn H, Bellon P. Microstructural evolution of nanolayered $\mathrm{Cu}-\mathrm{Nb}$ composites subjected to highpressure torsion. Acta Mater 2014;72:178-91.

30. Gode C, Yilmazer H, Ozdemir I, Todaka Y. Microstructural refinement and wear property of $\mathrm{Al}-\mathrm{Si}-\mathrm{Cu}$ composite subjected to extrusion and high-pressure torsion. Mater Sci Eng 2014;A618:377-84.

31. Sauvage $\mathrm{X}$, Wetscher F, Pareige P. Mechanical alloying of $\mathrm{Cu}$ and $\mathrm{Fe}$ induced by severe plastic deformation of a Cu-Fe composite. Acta Mater 2005;53:2127-35.

32. Akbarpour MR, Farvizi M, Lee DJ, Rezaei H, Kim HS. Effect of high-pressure torsion on the microstructure and strengthening mechanisms of hot-consolidated $\mathrm{Cu}-\mathrm{CNT}$ nanocomposite. Mater Sci Eng 2015;A638:289-95.

33. Sabbaghianrad S, Langdon TG. Developing superplasticity in an aluminum matrix composite processed by high-pressure torsion. Mater Sci Eng 2016;A655:36-43.

34. Han BQ, Langdon TG. Achieving enhanced ductility in an Al-6061 composite processed by severe plastic deformation. Mater Sci Eng 2005;A410-411:430-4.

35. Chen LJ, Ma CY, Stoica GM, Liaw PK, Xu C, Langdon TG. Mechanical behavior of a $6061 \mathrm{Al}$ alloy and an $\mathrm{Al}_{2} \mathrm{O}_{3} / 6061 \mathrm{Al}$ composite after equal-channel angular processing. Mater Sci Eng 2005;A410-411:472-5.

36. Figueiredo RB, Cetlin PR, Langdon TG. Using finite element modeling to examine the flow processes in quasi-constrained high-pressure torsion. Mater Sci Eng 2011;A528:8198-204. 
37. Figueiredo RB, Pereira PHR, Aguilar MTP, Cetlin PR, Langdon TG. Using finite element modeling to examine the temperature distribution in quasi-constrained highpressure torsion. Acta Mater 2012;60:3190-8.

38. Vorhauer A, Pippan R. On the homogeneity of deformation by high pressure torsion, Scripta Mater 2004;51:921-5.

39. Valiev RZ, Ivanisenko YV, Rauch EF, Baudelet B. Structure and deformation behaviour of Armco iron subjected to severe plastic deformation. Acta Mater 1996;44:4705-12.

40. Wetscher F, Vorhauer A, Stock R, Pippan R. Structural refinement of low alloyed steels during severe plastic deformation. Mater Sci Eng 2004;A387-389:809-16.

41. Shahmir H, Nili-Ahmadabadi M, Huang Y, Langdon TG. Evolution of microstructure and hardness in NiTi shape memory alloys processed by high-pressure torsion. J Mater Sci 2014;49:2998-3009.

42. Sharman K, Bazarnik P, Brynk T, Bulutsuz AG, Lewandowska M, Huang Y, Langdon TG. Enhancement in mechanical properties of a $\beta$-titanium alloy by high-pressure torsion. J Mater Res Technol 2015;4:79-83.

43. Xu C, Langdon TG. Influence of a round corner die on flow homogeneity in ECA pressing. Scripta Mater 2003;48:1-4.

44. Xu C, Langdon TG. Three-dimensional representations of hardness distributions after processing by high-pressure torsion. Mater Sci Eng 2009;A503:71-4.

45. Kawasaki M. Different models of hardness evolution in ultrafine-grained materials processed by high-pressure torsion. J Mater Sci 2014;49:18-34.

46. Sabbaghianrad S, Langdon TG. An evaluation of the saturation hardness in an ultrafinegrained aluminum 7075 alloy processed using different techniques. J Mater Sci 2015;50:4357-65.

47. Sabbaghianrad S, Langdon TG. A critical evaluation of the processing of an aluminum 7075 alloy using a combination of ECAP and HPT. Mater Sci Eng 2014;A596;52-8.

48. Xu C, Horita Z, Langdon TG. The evolution of homogeneity in an aluminum alloy processed using high-pressure torsion. Acta Mater 2008;56:5168-76.

49. Loucif A, Figueiredo RB, Baudin Th, Brisset F, Langdon TG. Microstructural evolution in an Al-6061 alloy processed by high-pressure torsion. Mater Sci Eng 2010;A527:4864-9.

50. Kawasaki M, Alhajeri SN, Xu C, Langdon TG. The development of hardness homogeneity in pure aluminum and aluminum alloy disks processed by high-pressure torsion. Mater Sci Eng 2011;A529:345-51.

51. Mohamed IF, Lee S, Edalati K, Horita Z, Hirosawa Sh, Matsuda K, Terada D. Aging behavior of Al 6061 alloy processed by high-pressure torsion and subsequent aging. Metall Mater Trans A 2015;46A:2664-73.

52. Khereddine AY, Larbi FH, Kawasaki M, Baudin T, Bradai D, Langdon TG. An examination of microstructural evolution in a $\mathrm{Cu}-\mathrm{Ni}-\mathrm{Si}$ alloy processed by HPT and ECAP. Mater Sci Eng 2013;A576:149-55.

53. Wang YC, Langdon TG. Influence of phase volume fractions on the processing of a Ti6Al-4V alloy by high-pressure torsion. Mater Sci Eng 2013;A559:861-7.

54. Estrin Y, Molotnikov A, Davies CHJ, Lapovok R. Strain gradient modeling of highpressure torsion. J Mech Phys Solids 2008;56:1186-202. 


\section{Figure captions}

Fig. 1 Schematic illustration of an HPT facility operating under quasi-constrained conditions.

Fig. 2 Optical micrographs showing the microstructures at the near-edge locations (a) in the unprocessed condition and after HPT processing through (b) 1/4, (c) 1/2, (d) 1, (e) 5 and (f) 10 turns.

Fig. 3 Phase maps showing the distributions of major elements in the unprocessed MMC: (a) overview of unprocessed condition and elemental maps for (b) $\mathrm{Al}$, (c) O, (d) Mg and (e) Si.

Fig. 4 SEM micrographs of the cross-sections of the MMC at the disk centers (a) for the unprocessed condition and after HPT processing through (b) 1/4, (c) 1/2, (d) 1 , (e) 5 and (f) 10 turns.

Fig. 5 SEM micrographs of the cross-sections of the MMC at the near-edge locations (a) for the unprocessed condition and after HPT processing through (b) 1/4, (c) 1/2, (d) 1, (e) 5 and (f) 10 turns.

Fig. 6 Values of the microhardness recorded along diameters of the disks after 1/4, 1/2. 1, 5 and 10 turns: the lower line at $\mathrm{Hv} \approx 56$ shows the unprocessed material.

Fig. 7 Two-dimensional color-coded contour maps showing the microhardness distributions across the surfaces of disks after HPT processing through (a) 1/4, (b) 1/2, (c) 1, (d) 5 and (e) 10 turns: the color key is shown at lower right.

Fig. 8 Three-dimensional color-coded contour maps showing the microhardness distributions across the surfaces of disks after HPT processing through (a) $1 / 4$, (b) $1 / 2$, (c) 1, (d) 5 and (e) 10 turns: the color key is shown at lower right.

Fig. 9 Variation of the Vickers microhardness with the equivalent strain showing the development of a saturation condition at equivalent strains above $\sim 50$.

Fig. 10 Variation of the Vickers microhardness with the inverse square root of the grain size illustrating a typical Hall-Petch linear relationship. 


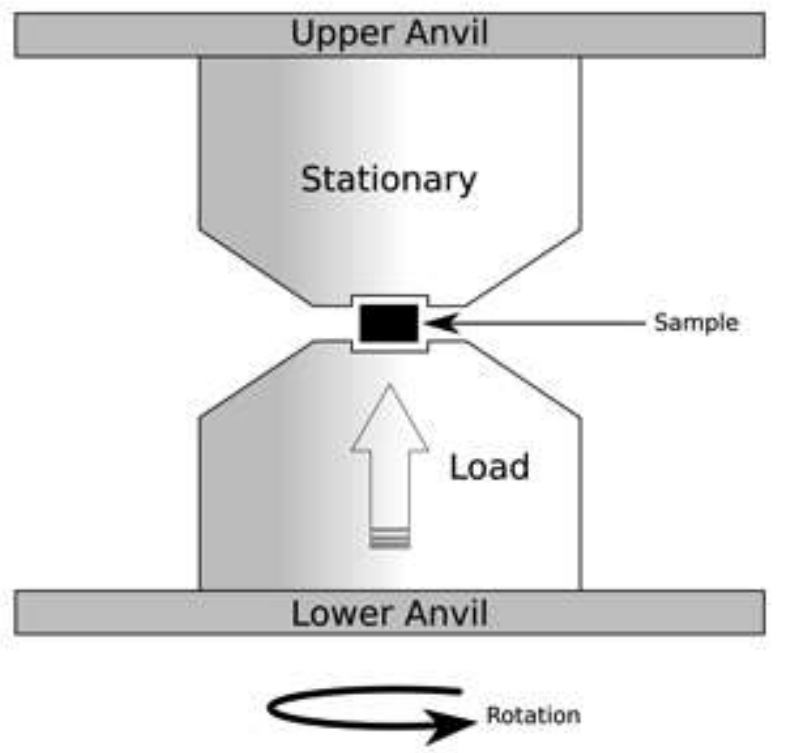

Fig. 1: Schematic illustration of an HPT facility operating under quasi-constrained conditions. 


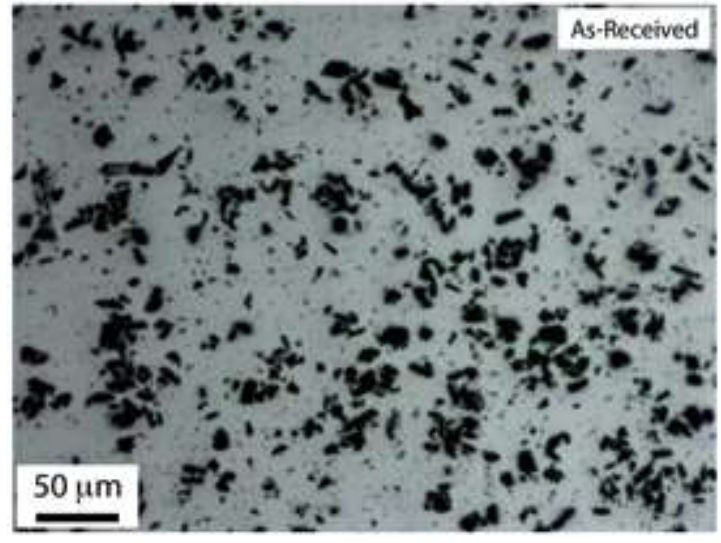

(a)

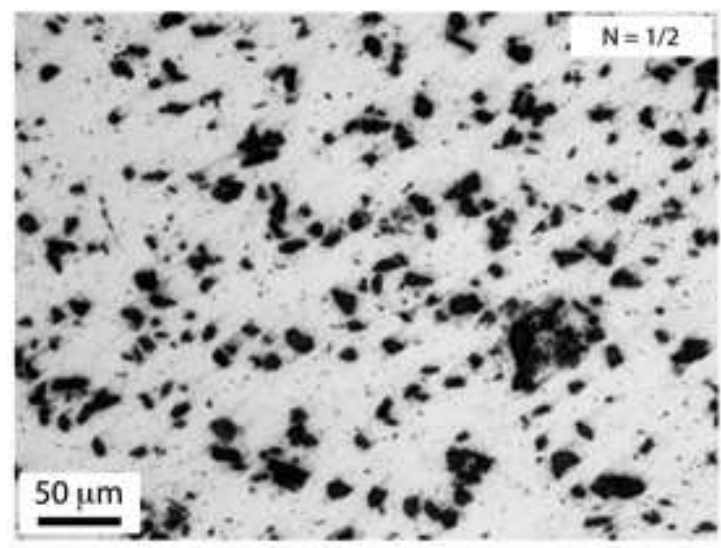

(c)

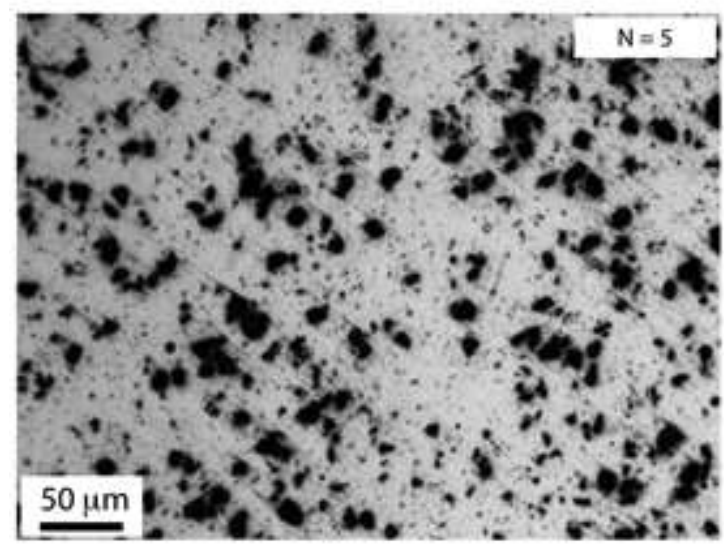

(e)

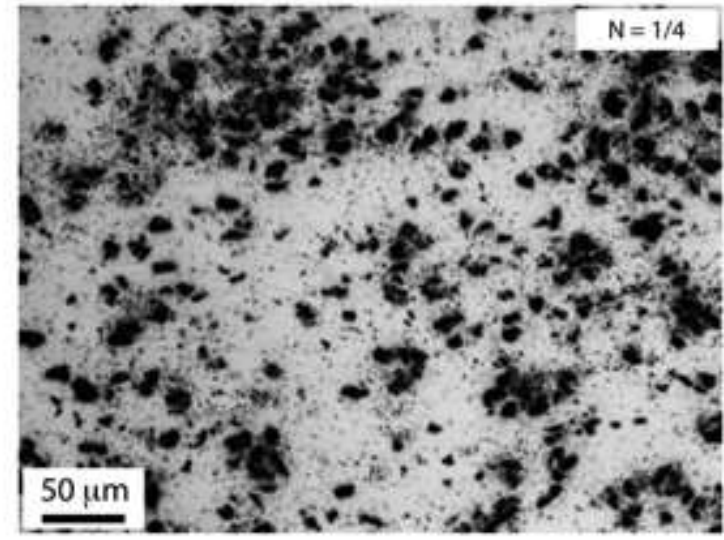

(b)

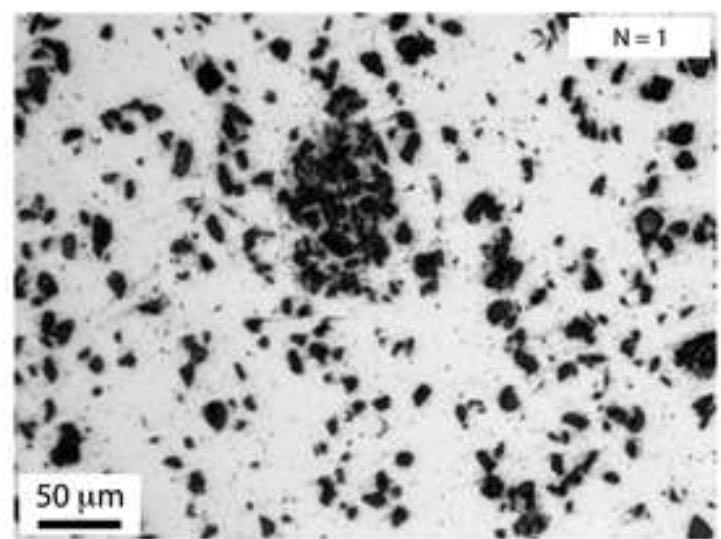

(d)

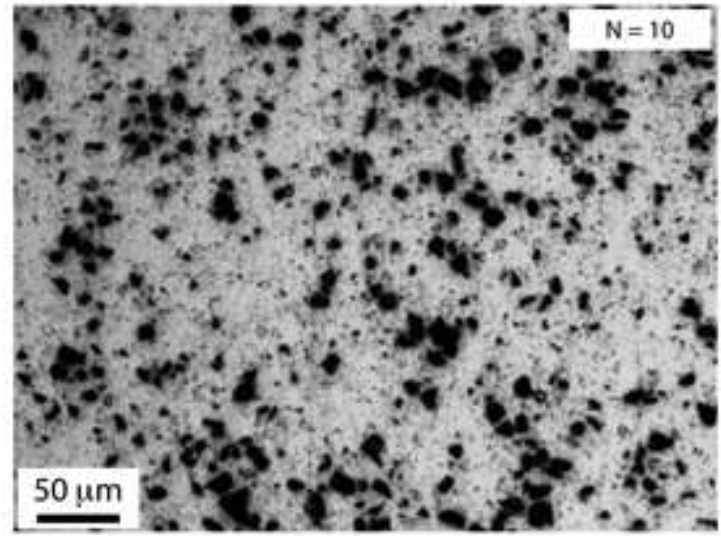

(f)

Fig. 2: Optical micrographs showing the microstructures at the near-edge locations (a) in the unprocessed condition and after HPT processing through (b) $1 / 4$, (c) $1 / 2$, (d) 1 , (e) 5 and (f) 10 turns. 


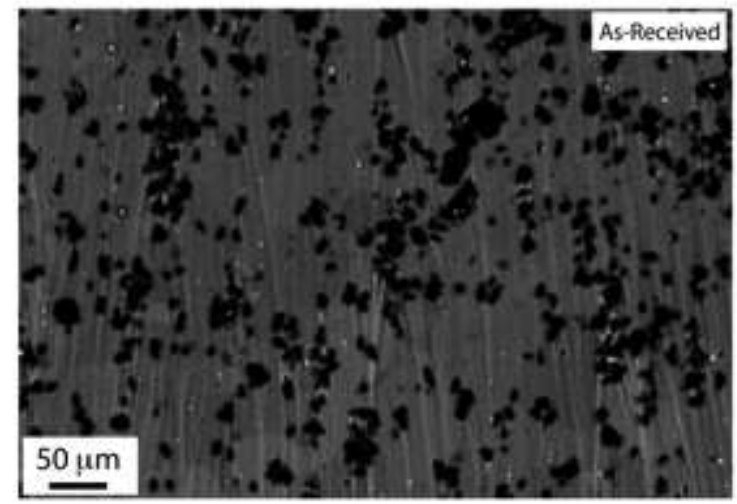

(a)

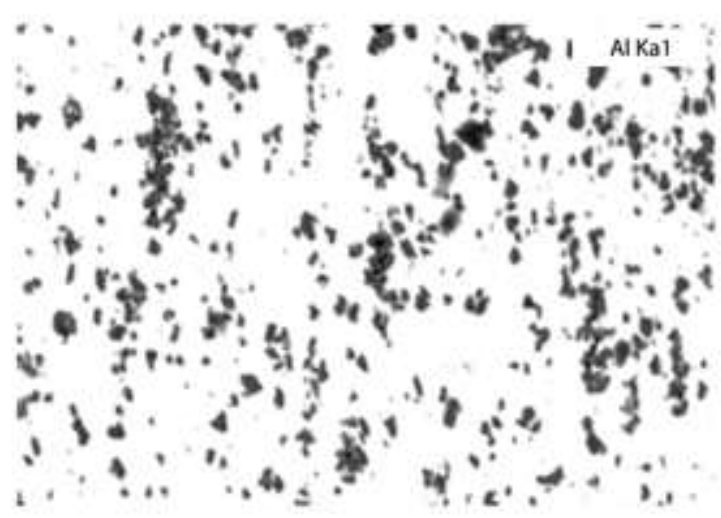

(b)

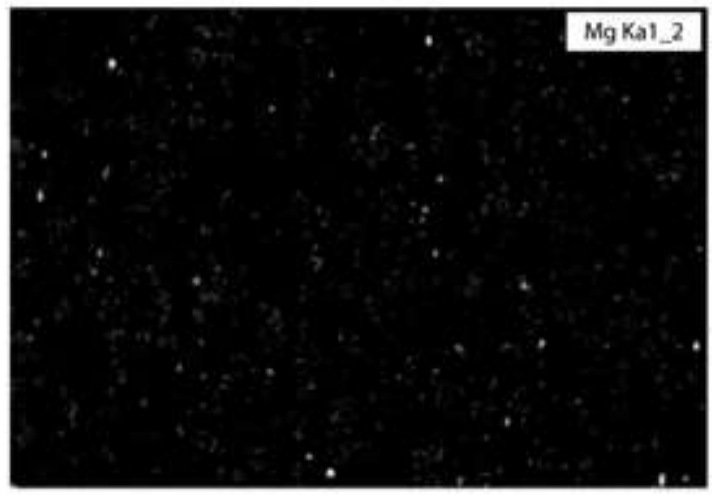

(d)

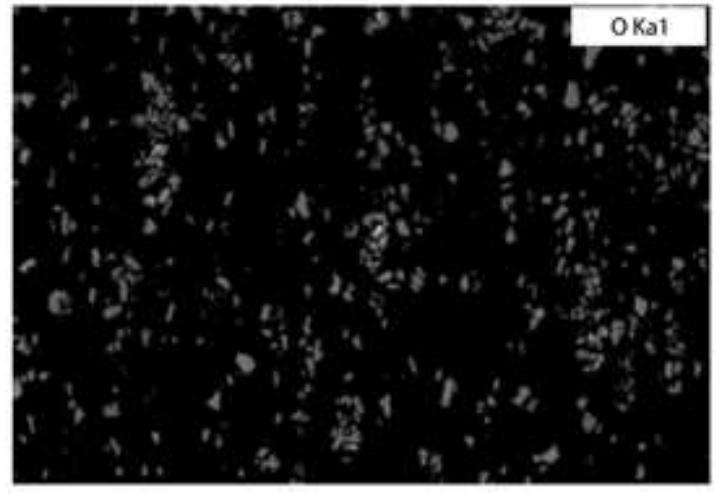

(c)

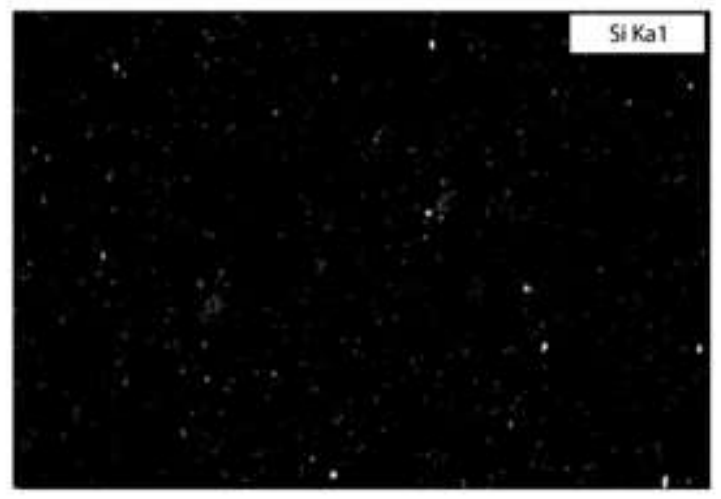

(e)

Fig. 3: Phase maps showing the distributions of major elements in the unprocessed MMC: (a) overview of unprocessed condition and elemental maps for (b) Al, (c) O, (d) $\mathrm{Mg}$ and (e) Si. 


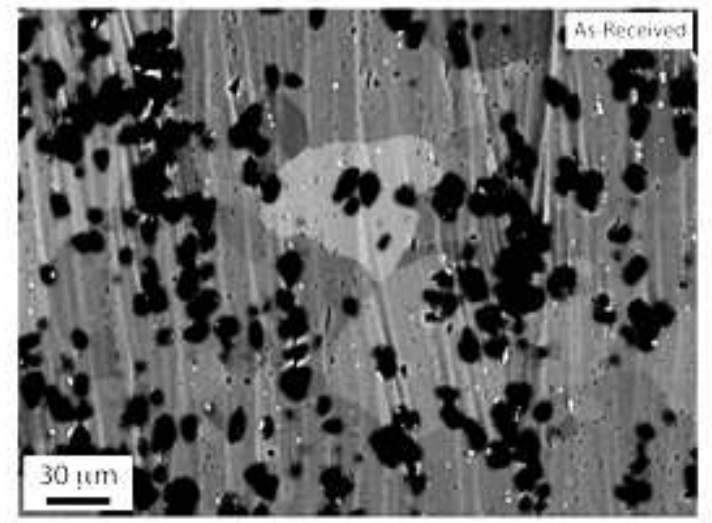

(a)

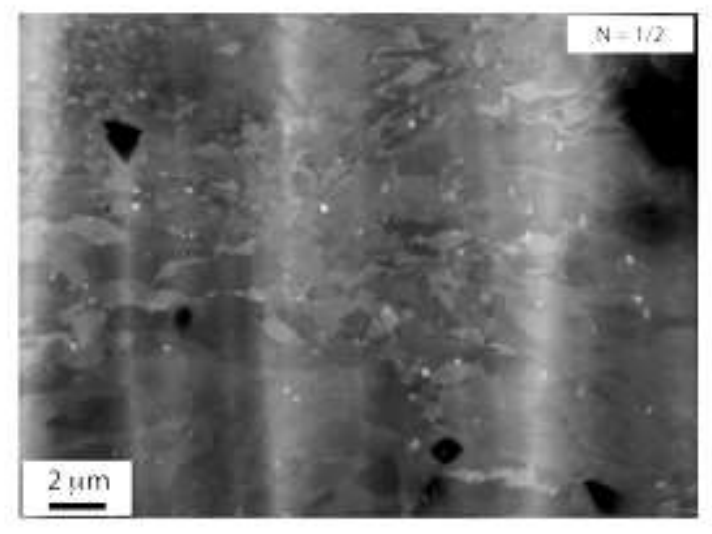

(c)

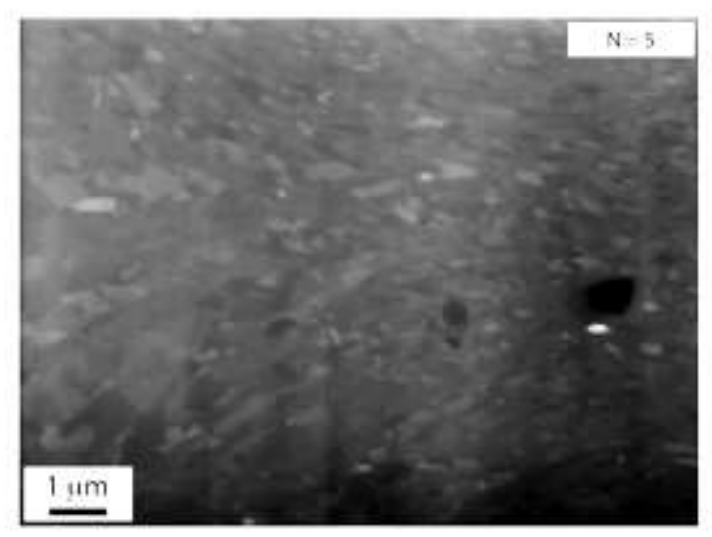

(e)

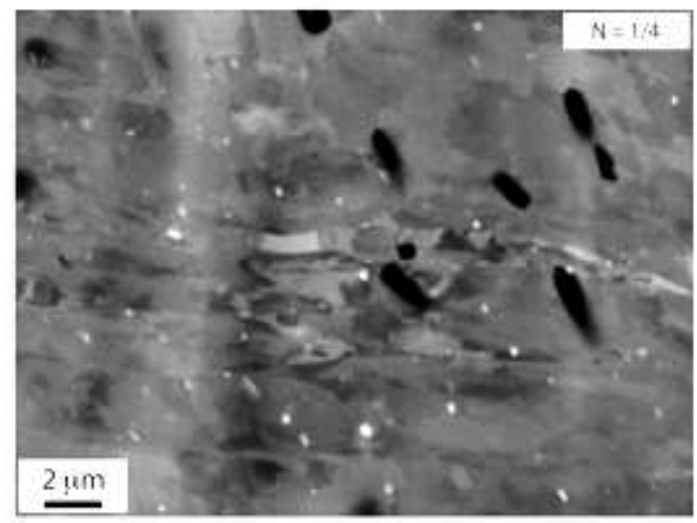

(b)

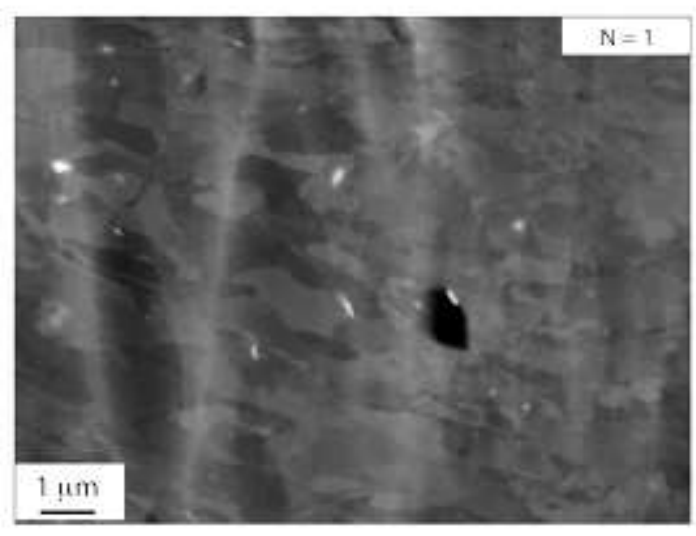

(d)

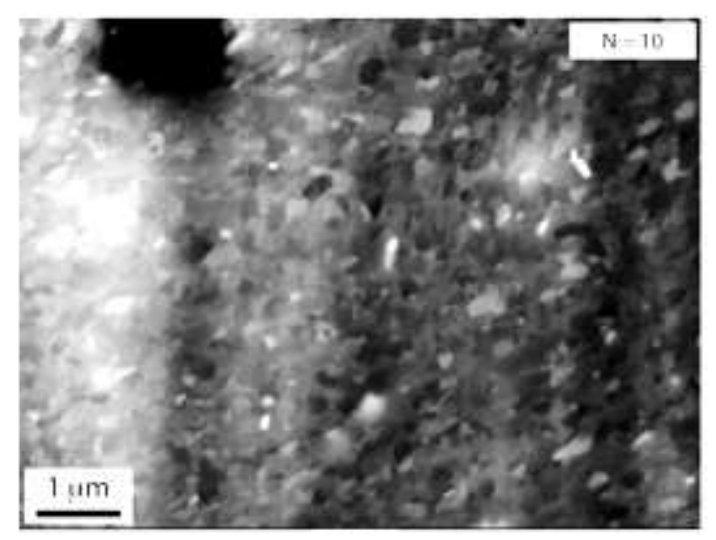

(f)

Fig. 4: SEM micrographs of the cross-sections of the MMC at the disk centers (a) for the unprocessed condition and after HPT processing through (b) $1 / 4$, (c) $1 / 2$, (d) 1 , (e) 5 and (f) 10 turns. 


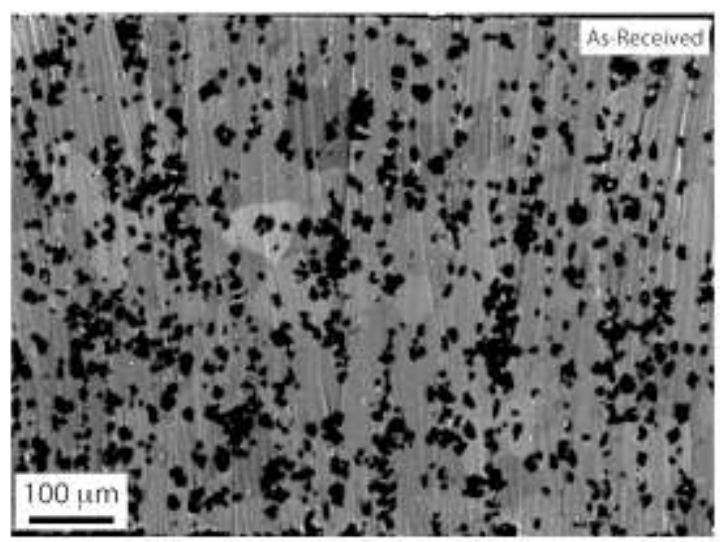

(a)

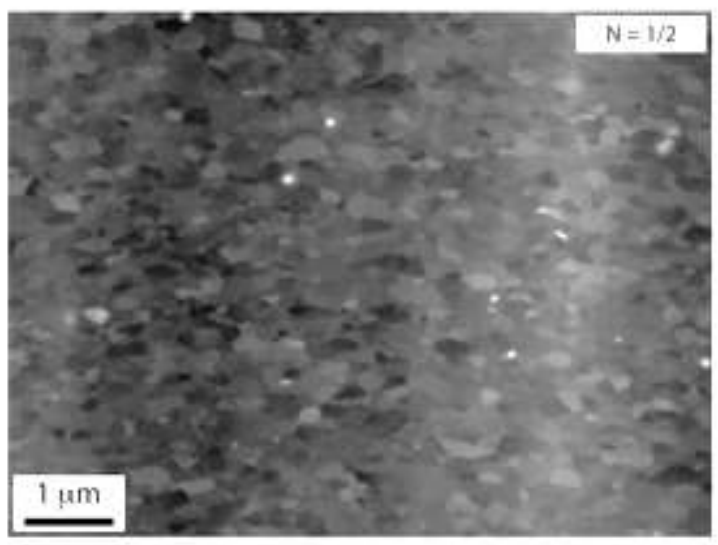

(c)

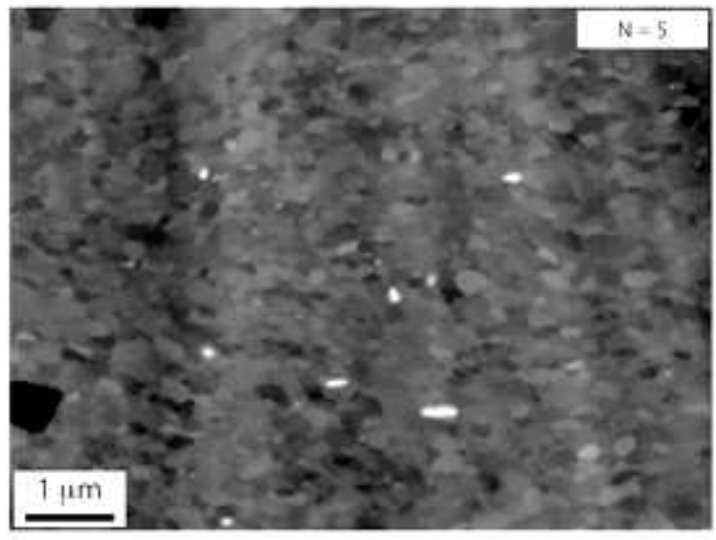

(e)

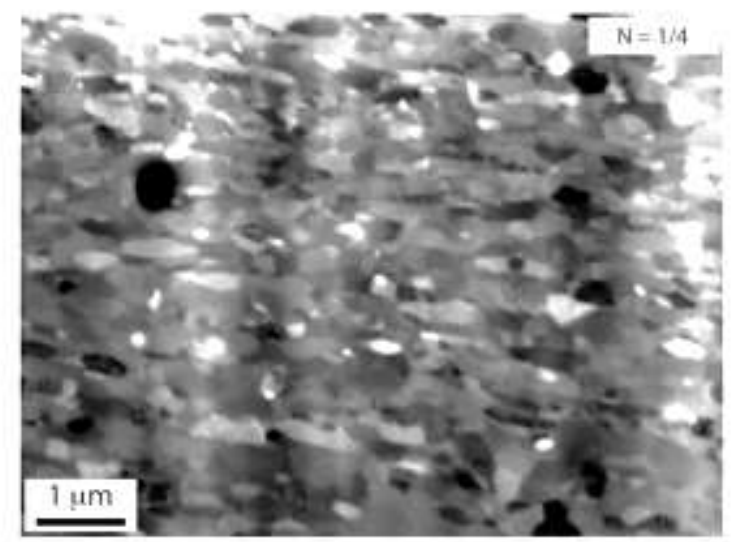

(b)

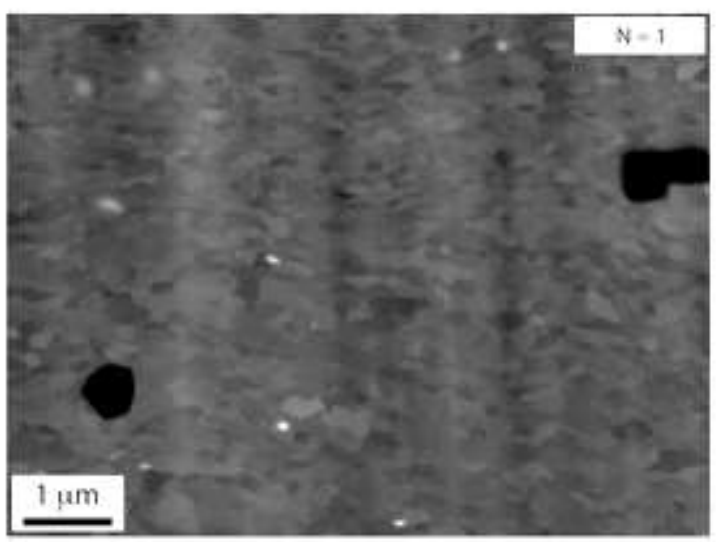

(d)

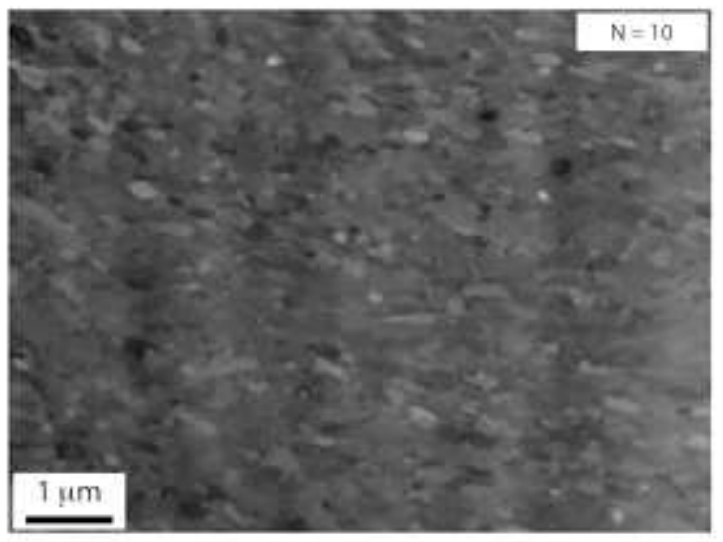

(f)

Fig. 5: SEM micrographs of the cross-sections of the MMC at the near-edge locations (a) for the unprocessed condition and after HPT processing through (b) $1 / 4$, (c) $1 / 2$, (d) 1 , (e) 5 and (f) 10 turns. 


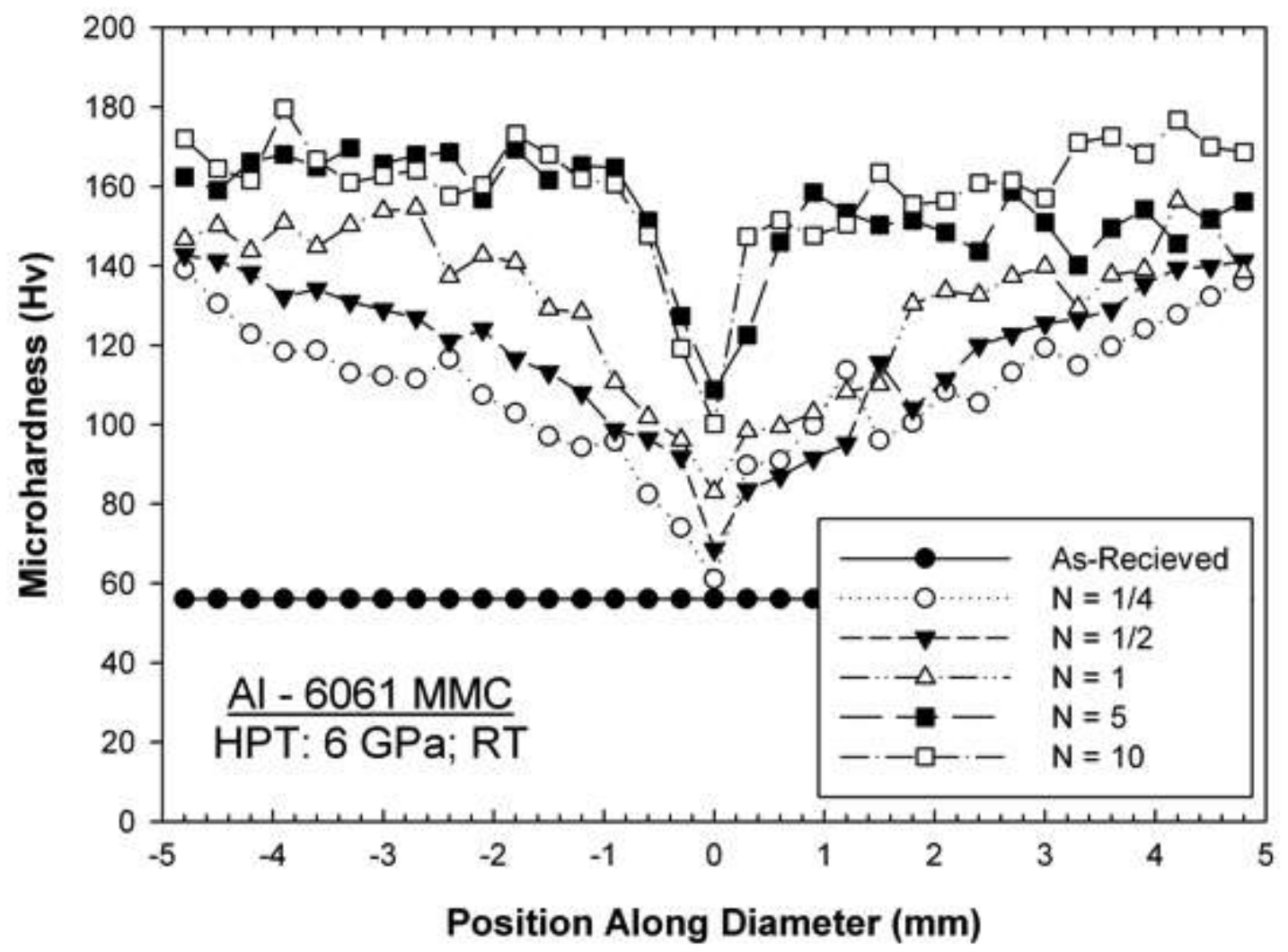

Fig. 6: Values of the microhardness recorded along diameters of the disks after 1/4, 1/2. 1,5 and 10 turns: the lower line at $\mathrm{Hv} \approx 56$ shows the unprocessed material. 


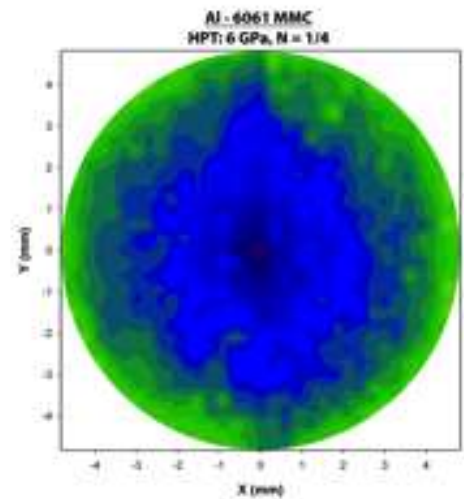

(a)

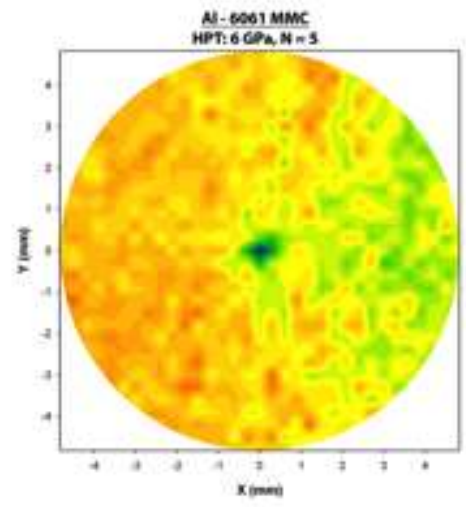

(d)

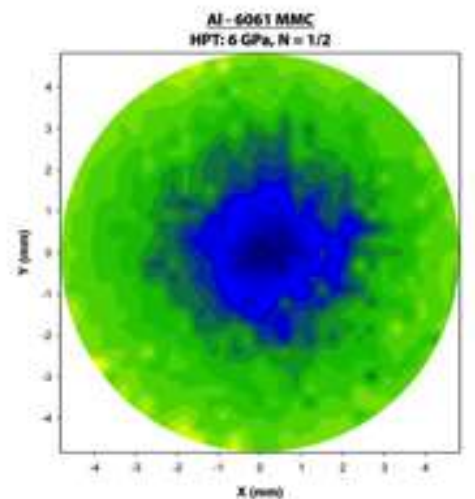

(b)

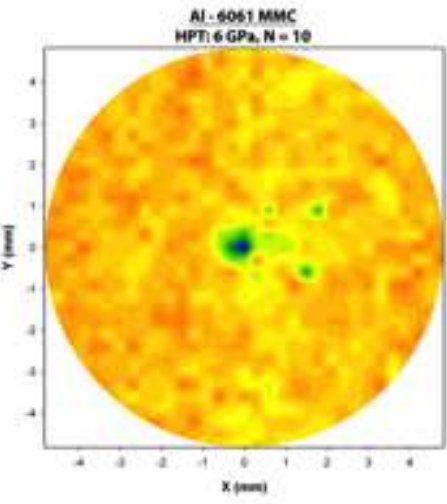

(e)

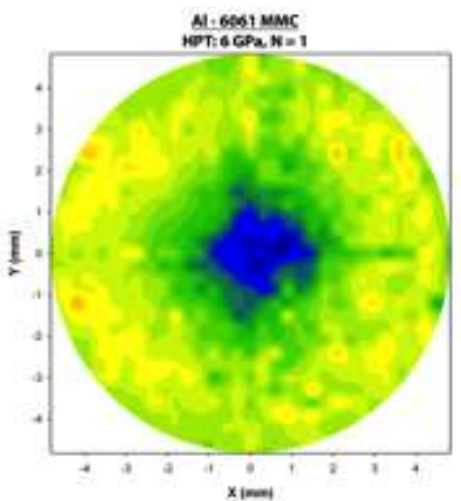

(c)

Fig. 7: Two-dimensional color-coded contour maps showing the microhardness distributions across the surfaces of disks after HPT processing through (a) 1/4, (b) 1/2, (c) 1, (d) 5 and (e) 10 turns: the color key is shown at lower right. 


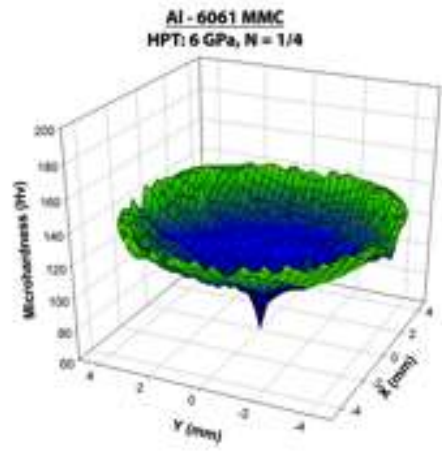

(a)

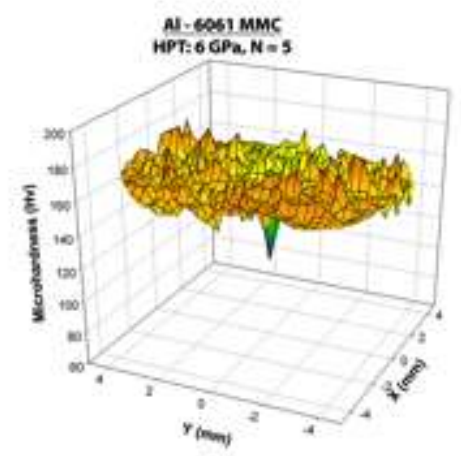

(d)

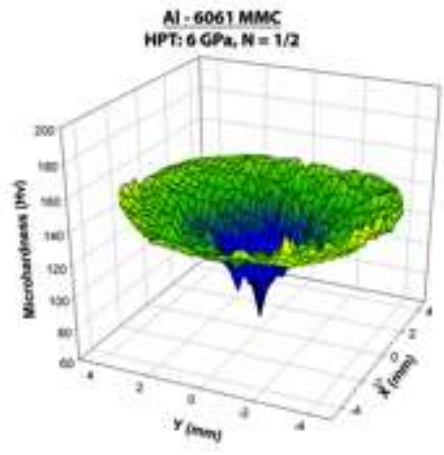

(b)

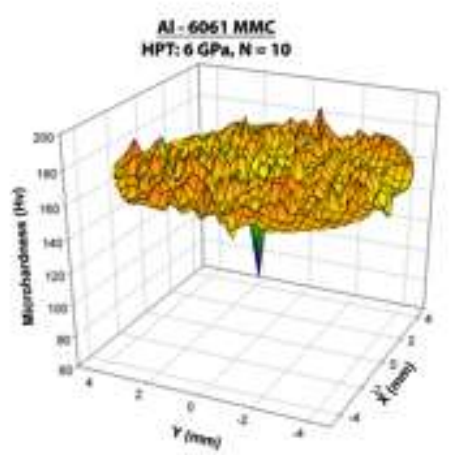

(e)

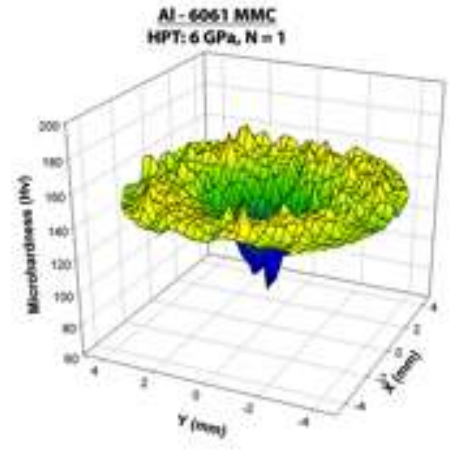

(c)

Fig. 8: Three-dimensional color-coded contour maps showing the microhardness distributions across the surfaces of disks after HPT processing through (a) 1/4, (b) 1/2, (c) 1, (d) 5 and (e) 10 turns: the color key is shown at lower right. 


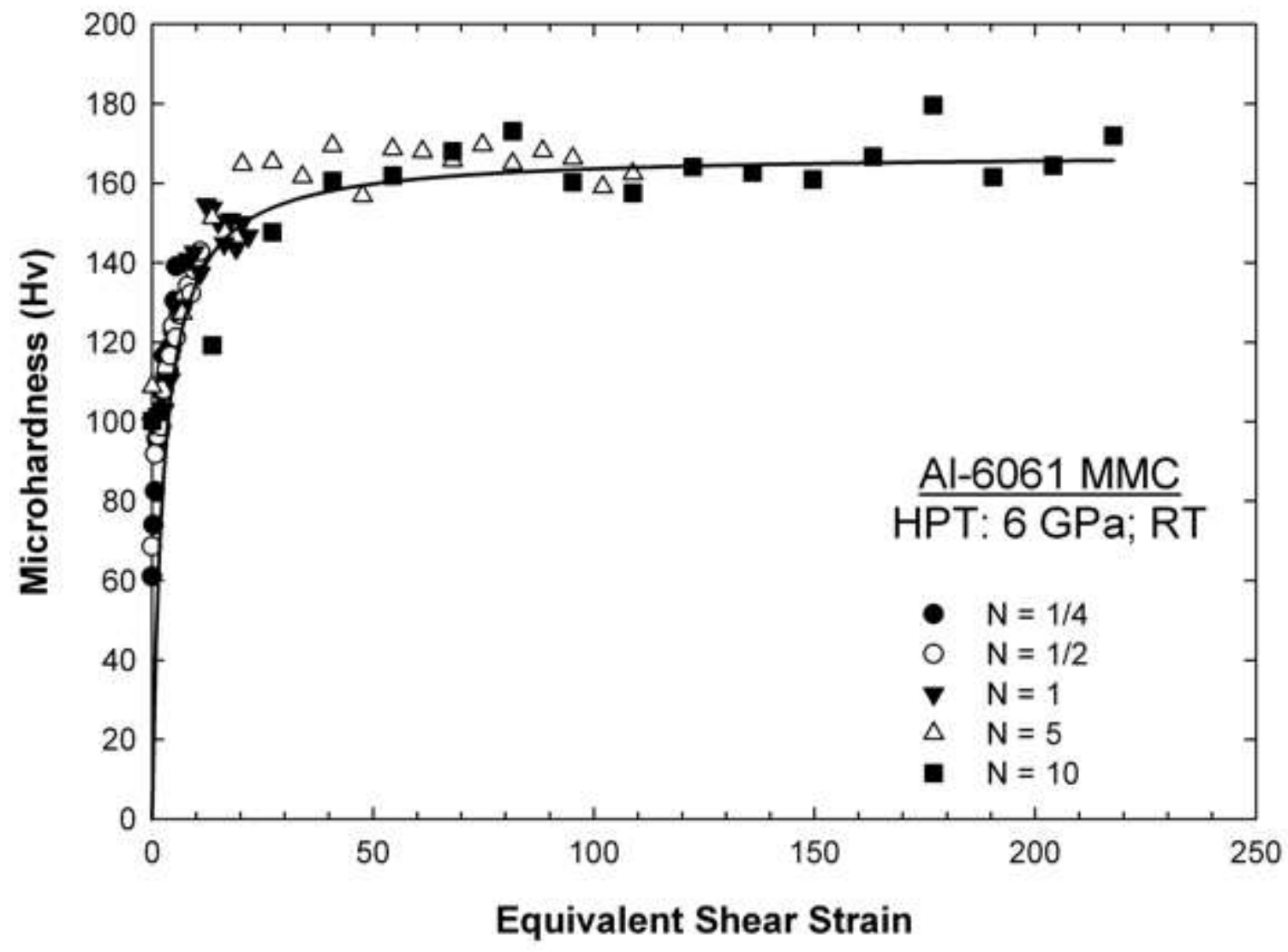

Fig. 9: Variation of the Vickers microhardness with the equivalent strain showing the development of a saturation condition at equivalent strains above $\sim 50$. 


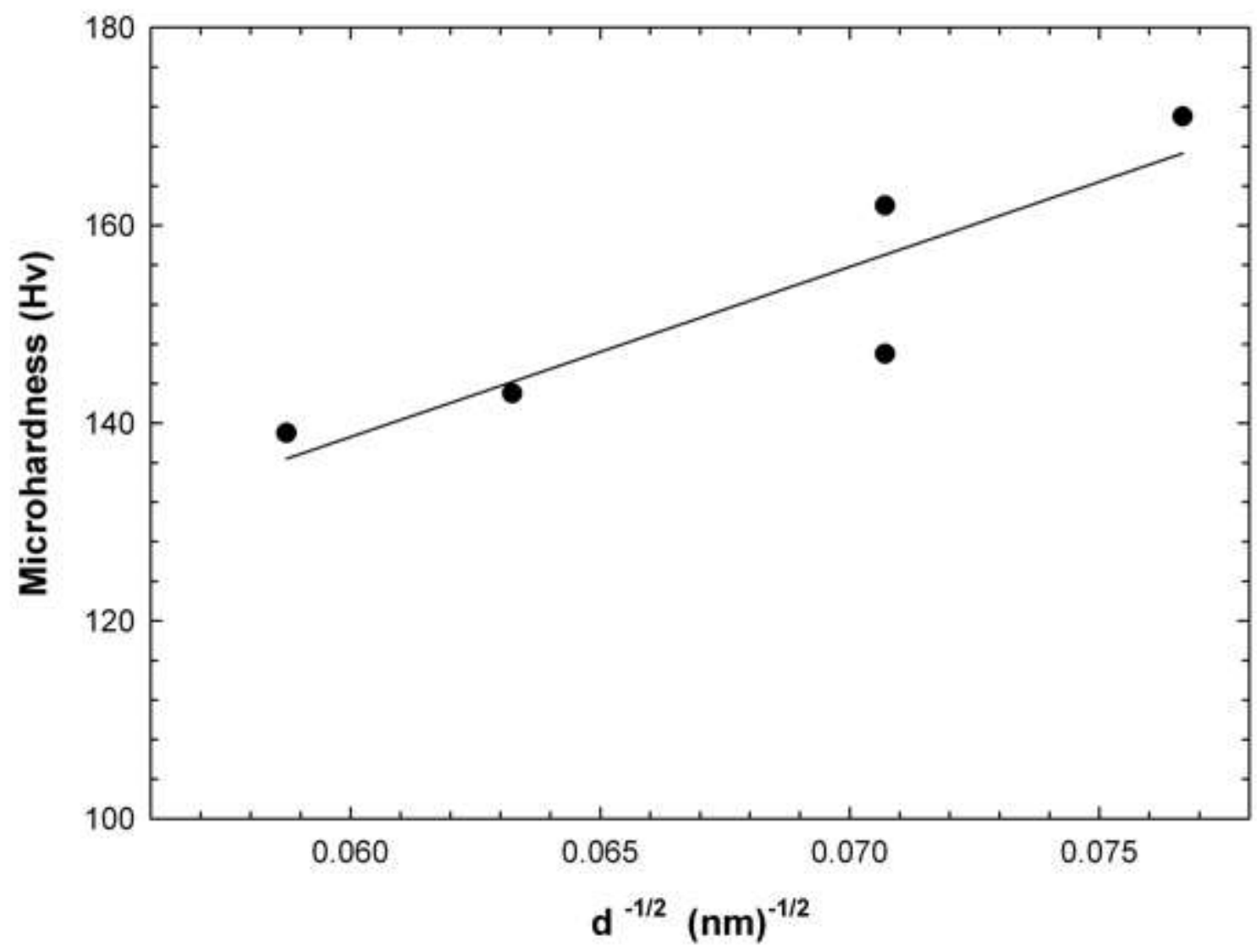

Fig. 10: Variation of the Vickers microhardness with the inverse square root of the grain size illustrating a typical Hall-Petch linear relationship. 